\title{
APRENDIZAGEM BASEADA EM PROBLEMAS NO ENSINO DE CIÊNCIAS: mudando atitudes de alunos e professores
}

\section{Learning based on science teaching problems: changing students and teachers' attitudes}

\author{
João Manoel da Silva Malheiro ${ }^{1}$ \\ Cristowam Wanderley Picanço Diniz ${ }^{2}$
}

\section{RESUMO}

O aprendizado baseado em problemas (APB) é apontado como ferramenta importante para ensinar os alunos a aprender com autonomia. $\mathrm{O}$ objetivo deste trabalho é comparar a forma habitual de ensinar Ciências e Biologia no Ensino Médio da Escola Pública com a metodologia da Aprendizagem Baseada em Problemas (ABP). Para tanto, dois Cursos de Férias frequentados por alunos e professores do ensino médio foram baseados na $\mathrm{ABP} e$ dedicados à redescoberta da anatomia do corpo de animais com estilos de vida contrastantes. Foram feitas análises qualitativas e quantitativas a partir de questionários aplicados antes e depois dos cursos a alunos e professores. Os resultados apontaram para maior motivação dos alunos e professores em ciências e biologia após os cursos de férias e para a possibilidade da utilização imediata da metodologia no ensino médio na escola pública a despeito das restrições atuais de infra-estrutura.

Palavras-chave: Ensino de Ciências, Aprendizado Baseado em Problemas, Escola Pública, Ensino Médio.

\footnotetext{
ABSTRACT

The problem based on learning (PBL) has been pointed out as an important tool to teach students how to learn by themselves. The aim of the present paper is to compare the usual way to deliver sciences and biology lectures at the Public High School with the problem based on learning (PBL). For this purpose two holiday courses based on PBL, were delivered to teachers and students of the High School and
}

dedicated to re-discover animals' anatomy with contrasting life styles. Quali-quantitative analysis were done applying questionnaires to the teachers before and after the courses. The results pointed to higher motivation of both students and teachers in sciences and biology after the holiday courses and suggested that it is possible to start with PBL methodology at the Public High School despite the present infrastructure limitations.

Keywords: Science teaching, Problem Based Learning, Public School, High School.

\section{INTRODUÇÃO}

Competente é o professor que, sentindo-se politicamente comprometido com seu aluno, conhece e utiliza adequadamente os recursos capazes de lhe propiciar uma aprendizagem real e plena de sentido. Competente é o professor que tudo faz para tornar seu aluno cidadão crítico e bem informado em condições de compreender e atuar no mundo em que vive (MOYSES, 1995, p.15).

A metodologia da Aprendizagem Baseada em Problemas (ABP) foi implantada no final da década de 60, na Universidade de McMaster, no Canadá, e, pouco depois, na Universidade de Maastricht, na Holanda. No Brasil, a Faculdade de Medicina de Marília e o curso de Medicina da Universidade Estadual de Londrina iniciaram um novo currículo baseado em ABP, em 1997 e 1998, respectivamente. Atualmente, muitas escolas em todo o mundo adotaram currículos baseados nesta metodologia (aproximadamente $10 \%$ ) (BERBEL, 1998, MALHEIRO, 2005), embora sua generalização esteja longe de ser alcançada.

Doutor em Educação para Ciência pela Universidade Estadual Paulista (UNESP/Bauru/2009). Professor assistente da Faculdade de Pedagogia da UFPA - Campus Castanhal.

Doutorado em Ciências Biológicas (Biofísica) pela Universidade Federal do Rio de Janeiro, Brasil(1987). Prof. ASSOCIADO NÍVEL 2 da Universidade Federal do Pará, Brasil. 
Desde já, podemos adiantar que o problema a que constantemente será feito referência não diz respeito aos pseudoproblemas expostos cotidianamente no ambiente da escola, mas à tarefa de aprender redescobrindo a partir da experimentação. É importante notar que "uma questão toma a dimensão de um problema, quando suscita a dúvida, estimula a solução e cria a necessidade de ir em busca de informações para que as soluções se apresentem" (BRASIL, 1997, p.127). O problema deve colocar os alunos diante de um grande número de decisões que eles devem tomar, criando estratégias com o objetivo de solucionar o que lhe foi proposto e traçado (PERRENOUD, 1999). Além disso, Perrenoud (Id. Ibdem, p.57) evidencia: "um problema deve estar de alguma maneira 'incluído' em uma situação que lhe dê sentido". Deve instigar os alunos a compreenderem os fenômenos em que estão imersos.

A ABP, assim como a problematização, "são ferramentas utilizadas para favorecer ao estudante a obtenção de conhecimentos, bem como habilidades e atitudes". Segundo Teixeira, "é uma estratégia pedagógica e um método de desenvolvimento curricular, que permite desenvolver simultaneamente estratégias para resolução de problemas, bases de conhecimentos disciplinares e competências". Segundo o autor, a principal característica dessa metodologia é o fato de ser centrada no aluno, desenvolver-se em pequenos grupos tutoriais, apresentar problemas em um determinado contexto, ser um processo ativo, cooperativo, integrado e interdisciplinar. A ABP visa, dentre outras coisas, a estimular no aluno a capacidade de aprender a aprender, de trabalhar em equipe, de ouvir outras opiniões, mesmo que contrárias às suas e induz o aluno a assumir um papel ativo e responsável pelo seu aprendizado. Objetiva também conscientizar o aluno do que ele sabe e do que precisa aprender, motivando-o a ir buscar as informações relevantes.

Gadotti (2004, p.21) afirma que "se aprende o que é significativo para o projeto de vida das pessoas. Aprende-se quando se tem um projeto de vida. Aprendemos a vida toda. Não há tempo próprio para aprender".

$O$ método $\mathrm{ABP}$ exige uma mudança drástica no fazer pedagógico docente (tutor), que desce do pedestal do transmissor de informações e transforma-se em estimulador e parceiro dos estudantes na descoberta e construção do conhecimento.

$\mathrm{O}$ método ABP foi desenhado para determinar nos envolvidos (professores e alunos) a capacidade de pensar sobre os problemas apresentados e as possíveis ferramentas que serão utilizadas para resolvêlos. Deste modo, o tutor orienta todas as discussões dos alunos, de modo a abordar os objetivos, previamente definidos, a serem alcançados naquele problema e estimula o aprofundamento e discussão. Em nenhum momento, pode dar informações técnicas sobre a temática em discussão.

Segundo Alves (2003a, p. 56):

O pensamento é como uma águia que só alça voo nos espaços vazios do desconhecido. Pensar é voar sobre o que não se sabe. Não existe nada mais fatal para o pensamento que o ensino de respostas certas. Para isso existem as escolas: não para ensinar as respostas, mas para ensinar as perguntas. As respostas nos permitem andar sobre a terra firme, mas somente as perguntas nos permitem entrar pelo mar desconhecido.

O tutor facilita a dinâmica grupal e avalia os alunos sob o foco cognitivo e comportamental.

No ABP, o papel do aluno destaca-se por apresentar: participação ativa nas discussões realizadas, contribuir com seus conhecimentos e experiências prévias em todas as reuniões, colaborar com os conhecimentos adquiridos, justificando-os com as referências bibliográficas pesquisadas, ou seja, devem ajudar o grupo a solucionar o problema. Ao revelar por si só, com um pequeno auxílio do professor, o que era desconhecido, o indivíduo conquista melhores condições de aprender.

A utilização do Método Científico bem como da experimentação, dentro da perspectiva da ABP, tem como objetivo mostrar aos alunos como a Ciência e a pesquisa se estabelecem, transformando o aluno de mero copiador de conteúdos propostos, para o agente fiel da construção dos próprios conhecimentos redescobertos.

O MÉTODO CIENTÍFICO E A APRENDIZAGEM BASEADA EM PROBLEMAS

Acreditamos que, se questionada, a grande 
maioria dos professores, concordaria que uma das finalidades principais e essenciais da educação é a de desenvolver nos discentes, a perspicácia e a astúcia na resolução de problemas.

Por isso, muitos textos oficiais, como por exemplo, os PCN (BRASIL, 1997), suscitam a urgência em desenvolver o pensamento crítico e as competências na resolução de problemas. A Aprendizagem Baseada em Problemas, enquanto técnica de ensino voltada para o Ensino de Ciências, encontra-se calcada na perspectiva da formulação de um problema que possa desestabilizar o estado de inércia que, em geral, o aluno se encontra na sala de aula.

Após essa excitação inicial, surge um momento de dúvida, que irá fazer com que os educandos mobilizem aspectos cognitivos, para tentar elucidar o problema. Com isso, podemos notar que, na perspectiva da $\mathrm{ABP}$ é necessário que o professor possa ter consciência que a formulação de um problema bem elaborado é fundamental para que possa levar os alunos à perplexidade. Alves (2003) afirma que uma das tarefas mais alegres de um educador é provocar nos seus alunos a experiência do espanto. Um aluno espantado é um aluno pensante e, consequentemente, mais crítico acerca da problemática apresentada.

O problema na ABP deve motivar o aluno a buscar, quando possível, respaldo na experimentação calcada no método científico, meios diversos que estejam ao seu alcance para resolução dos problemas propostos.

A parceria ABP e Método Científico, nessa definição, é necessária como instrumento mediador entre o que está posto nas entrelinhas dos problemas e o que o aluno pode fazer para redescobrir. Muitas vezes, apesar de os alunos se debruçarem sobre livros, e viajarem por horas na internet, muitos problemas acabam não tendo de maneira clara suas respostas apresentadas nos diversos meios didáticos averiguados. O método científico pode fornecer a esses alunos uma forma concreta de constatar ou não a veracidade das hipóteses por eles levantadas. Num caso e noutro, a descoberta gera o "espanto" necessário à consolidação do aprendizado.

A experimentação proporcionará ao grupo tutorial como um todo a possibilidade de construir os seus próprios caminhos, o caminhar com os próprios pés, no sentido de passarem da condição de inércia que o ensino tradicional estabelece, para agentes construtores dos próprios conhecimentos. Estarão assim preparados para aprender a aprender e tornar esse aprendizado significativo para sua vida.

\section{PROCEDIMENTOS METODOLÓGICOS DE PESQUISA: O CURSO DE FÉRIAS: UM MODELO DE APRENDIZAGEM BASEADA EM PROBLEMAS}

A metodologia da Aprendizagem Baseada em Problemas foi posta à prova neste trabalho durante o primeiro e o segundo Curso de Férias Desvendando o Corpo dos Animais, que aconteceu no mês de julho de 2004 e fevereiro de 2005 , respectivamente.

O curso foi desenhado como um modelo para formação de formadores e como instrumento de seleção para inclusão de alunos de ensino médio que vivem em condições de risco, em um programa de iniciação científica precoce. Esse programa recebe o suporte financeiro da Fundação VITAE e ocorreu em sua terceira versão, razão pela qual não é objeto deste documento avaliar seu impacto de longo prazo. O curso visa a buscar alternativas viáveis que permitam a preparação do professor para enfrentar os novos tempos de currículos descartáveis decorrentes da explosão do conhecimento científico.

\section{ADINÂMICADO CURSO}

Para a integralização do curso, foram adotados quatro sistemas físiológicos. Alunos e professores puderam através da observação e experimentação rever seus conhecimentos prévios obtidos no Ensino Fundamental e Médio, bem como obter respostas para seus questionamentos sobre os sistemas abordados. Assim, a análise minuciosa das peças anatômicas comparativas entre os diversos grupos de animais (aves, anfíbios, répteis e mamíferos) observados e a experimentação cientifica permitiu correlações entre a forma e a função de órgãos de animais que ocupam diferentes ecossistemas. 


\section{OS CURSOS DE FÉRIAS: Avaliação dos discentes.}

Foram aplicados questionários do tipo misto, no início e no final dos cursos de férias.

As perguntas, de um modo geral, buscaram verificar, entre outras coisas, como os alunos percebiam a sua participação, interesse e motivação, durante as aulas. Buscamos saber também se os seus professores utilizavam algum recurso pedagógico, além do quadro e giz, para dinamizar suas aulas. Foi objeto também deste questionário identificar se os alunos constatavam a importância dos conteúdos trabalhados por seus professores para resolverem problemas do dia-a-dia.

Os principais depoimentos são apresentados no quadro abaixo, sendo os nomes dos sujeitos investigados fictícios:

\begin{tabular}{|l|l|}
\hline Alunos(as) & \multicolumn{1}{|c|}{ Depoimentos } \\
\hline Maria & $\begin{array}{l}\text { a aula só falada se torna chata e cansativa, por justamente faltar os recursos } \\
\text { pedagógicos. Só a leitura dá sono nos colegas. Os alunos não são estimulados } \\
\text { e os procedimentos são sempre iguais, caracterizando a mesmice. O único } \\
\text { recurso que o professor utiliza para dar as aulas é o quadro, o giz e a apostila } \\
\text { (ou livro). }\end{array}$ \\
\hline João & $\begin{array}{l}\text { as aulas deveriam ser 30\% de teoria e 70\% de prática, ou seja, os professores } \\
\text { deveriam utilizar sempre experiências. }\end{array}$ \\
\hline Márcia & $\begin{array}{l}\text { se houvesse estímulo por parte dos professores, levando dinâmicas, } \\
\text { modificando as aulas, tenho certeza que minha participaçâo e o meu } \\
\text { desempenho iriam se modificar. Não gosto muito de Biologia mas esse curso } \\
\text { mefez refletir que a Biologia não é tão ruim. Porque com as experiências, me } \\
\text { fez pensar e gostar cada vez mais de descobrir certas coisas diferentes. }\end{array}$ \\
\hline Manoel & $\begin{array}{l}\text { o professor não se esforça nem um pouco. Como eu posso estudar e aprender } \\
\text { a matéria? }\end{array}$ \\
\hline Vitor & $\begin{array}{l}\text { sempre procuro me empenhar e tirar minhas dúvidas, pois preciso aprender } \\
\text { para responder as questões do vestibular. É muito dificil aprender com } \\
\text { aluno. Só vão bater o ponto. }\end{array}$ \\
\hline
\end{tabular}

Assim, os alunos vão se posicionando, com perspectivas muito semelhantes, principalmente em seu desejo de participarem de aulas mais dinâmicas e calcadas na experimentação. $\mathrm{Na}$ grande maioria dos depoimentos levantados, a experimentação e, consequentemente, a utilização do Método Científico, são as grandes ausências durante as aulas de Ciências/Biologia.

As questões que buscavam aferir o grau de motivação dos alunos como um todo durantes as aulas de Ciências e Biologia situavam-se entre regular e ruim, devido à ausência de recursos didáticos e dinâmicas que pudessem mudar o papel dos alunos de coadjuvantes para o de atores principais do processo.

Além do relatado acima, é importante ressaltar que aproximadamente $80 \%$ dos entrevistados afirmaram que os alunos só participam das atividades indicadas pelos docentes se as mesmas fossem "valendo ponto para prova". Outro ponto que chamou atenção foi quando cerca de $90 \%$ das respostas dos alunos apontou que os conteúdos trabalhados pelos professores e monitores do Curso de Férias "têm relação com tudo o que interessa para nós e estão fazendo parte da nossa vida todo dia e os mesmos ajudam a entender muitos problemas enfrentados no nosso dia-a-dia".

A última pergunta apresentada pedia que os mesmos traçassem um perfil de como gostariam que fossem as aulas de Ciências e Biologia. As principais falas reúnem-se nestes pronunciamentos: 
Que fossem utilizados laboratórios e equipamentos necessários para a prática das experiências

Aulas teóricas e práticas para ver se confirmam ou não a teoria;

Não ficar preso à apostila. Deve mostrar como acontece;

Professores mais compreensivos porque tem gente que tem muita dificuldade de aprender

Assim, entre queixas e esperanças por dias melhores, os discentes participantes dos cursos colocaram seus julgamentos acerca da dinâmica da escola em que estudam.

OS CURSOS DE FÉRIAS: Avaliação dos Professores do Ensino Médio

As perguntas que deram suporte à pesquisa foram centradas nos mesmos questionamentos feitos aos alunos nos referidos cursos, para que pudéssemos avaliar se os pronunciamentos docentes encontravam eco nos dizeres discentes.

Pudemos perceber que cerca de $70 \%$ dos professores afirmavam que o grau de interesse dos alunos por suas aulas estava entre os conceitos regular e ruim. $\mathrm{O}$ conceito excelente não foi mencionado por nenhum dos entrevistados. Assim, vários professores, durante as questões, ponderaram muitas justificativas para sustentar as apreciações abaixo do razoável quando se tratava do interesse dos alunos. Entre as quais, destacamos:

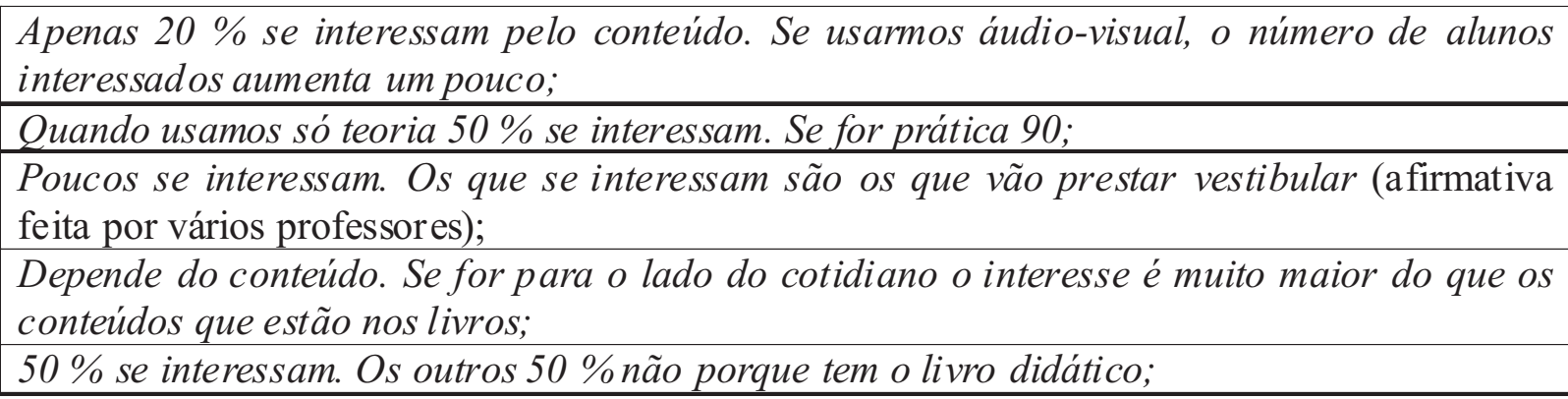

Genericamente, as falas acima caracterizam de maneira significativa o que pensa a grande maioria dos professores entrevistados.

Com relação aos recursos didáticos, constatamos que todos os professores utilizam basicamente quadro e giz (ou pincel), justificando o fato pela deficiência dos recursos pedagógicos nas escolas em que lecionam. O uso de apostilas também foi apontado pelos professores (cerca de $40 \%$ ), embora afirmem que muitos alunos não podem adquiri-las devido ao baixo poder aquisitivo dos mesmos.
Um grupo considerável de professores (60 $\%)$ também assegurou que utilizam vez por outra transparências para mostrar aos alunos algumas figuras que as apostilas e/ou livros didáticos não contêm. $\mathrm{O}$ uso do laboratório só foi apontado por um professor. O mesmo disse que no laboratório os alunos seguem sempre um roteiro elaborado por ele para verificação de uma teoria.

Dos professores investigados, a grande maioria considera o interesse de seus alunos regular. Apesar disso, afirmaram também que os mesmos só realizam alguma atividade se for valendo ponto para prova. Assim, transcrevemos a seguir alguns depoimentos: 
$O$ desinteresse está porque as aulas são só teóricas;

A falta de interesse é devido a fatores externos e internos (como no caso da escola);

São pouco participativos. É necessário algo que desperte mais curiosidade e interesse;

Não acho que seja minha a responsabilidade pelo fato de eles não estarem dando importância aos estudos. Creio que a falta de interesse dos alunos está na falta de perspectiva que eles não encontram, principalmente na família, então, a participação deles durante as aulas é mínima, ou seja, se reduz a copiar e esperar pelo colega CDF da turma para colarem.

Diante dessas constatações, passamos a analisar o quesito que discorria sobre a visão docente acerca da motivação dos alunos. Mais uma vez, constatamos que nenhum professor entrevistado considerou o conceito excelente para seus alunos. Sendo assim, a motivação discente oscilou entre os conceitos bom, regular e ruim.

Do mesmo modo que o formulário discente, a última pergunta para os professores versou sobre como eles gostariam que fossem as suas aulas. As falas que sintetizam o pronunciamento da maior parte dos entrevistados, em ordem decrescente de votação, estão compiladas abaixo:

Assim como para os alunos, o objetivo das perguntas realizadas era tentar identificar de que maneira os professores enxergavam a

\begin{tabular}{|l|}
\hline Gostaria que as aulas fossem mais práticas e participativas; \\
\hline Que tivesse laboratórios para os alunos terem contato com o que é dado na teoria; \\
\hline Redução do número de alunos; \\
\hline Um dia espero ministrar minhas aulas numa escola sem paredes, ou seja, que o aluno, a \\
partir da observação do meio que o cerca, construiria os seus próprios conceitos. \\
\hline
\end{tabular}

possibilidade de utilizar a Aprendizagem Baseada em Problemas, como estratégia real de ensino, a ser utilizada no ambiente escolar, buscando a parceria dos alunos, como já apontado em várias declarações prévias.
Desta feita, a questão investigada entre os docentes buscava perceber a possibilidade ou não da metodologia $A B P$ ser colocada em prática nas escolas. Os principais pronunciamentos feitos pelos educadores são transcritos a seguir.

\begin{tabular}{l}
\hline Esta metodologia gera alunos críticos, reflexivos, criativos e não receptores de conteúdos; \\
\hline $\begin{array}{l}\text { A metodologia seria uma das melhores técnicas de apoio ao professor, mas, infelizmente, } \\
\text { sem um apoio financeiro para renovação e compra de materiais fica dificil; }\end{array}$ \\
\hline $\begin{array}{l}\text { Sim, porém temos que considerar que sala com cinquenta alunos e não dispor de monitores } \\
\text { para apoiar, fica muito dificil; }\end{array}$ \\
\hline $\begin{array}{l}\text { Acredito que fomos orientados a repensar nossa maneira de passar os conteúdos, com isso, } \\
\text { aprendemos a usar outros recursos para valorizar nossas aulas; }\end{array}$ \\
\hline $\begin{array}{l}\text { Pode ser viável sim, desde que se busquem parcerias, principalmente para ajudarem a infra- } \\
\text { estrutura da escola; }\end{array}$ \\
\hline Sim, se o assunto ministrado não necessitar de uma grande quantidade de materiais; \\
\hline $\begin{array}{l}\text { Sim, pois os professores aprenderam a improvisar experimentos com os materiais existentes } \\
\text { na escola ou materiais que ele e os alunos têm em casa dá para trabalhar a metodologia por } \\
\text { redescoberta; }\end{array}$ \\
\hline $\begin{array}{l}\text { Sim, mas esporadicamente ou se não o conteúdo escolar será comprometido e que o } \\
\text { professor esteja aberto para o novo e o improviso de resolver problemas surgidos na hora. }\end{array}$ \\
\hline
\end{tabular}




\section{DOS DISCURSOS DOCENTES E DISCENTES Às POSSIBILIDADES DE MUDANÇA.}

A possibilidade de, por dois períodos consecutivos, ter acompanhado todo o transcorrer dos Cursos de Férias, se por um lado foi muito gratificante, por outro, foi constrangedor constatar que, apesar das evidências mostrarem a possibilidade real de se aplicar a ABP na escola, muitos professores manifestam certo ceticismo quanto à perspectiva de inovar no cotidiano escolar. $\mathrm{O}$ depoimento de alguns professores participantes dos cursos aponta para a permanência do status quo do ambiente escolar.

Assim, a vivência no fazer pedagógico dos cursos de férias mostrou, para nós e para alguns professores e todos os alunos, que a mudança é possível. Para tanto, é necessário que os educadores aceitem conscientes os seus não saberes que, vez por outra, o Método Científico e a ABP mostraram para todos do curso. É preciso que estejam estimulados e dispostos a fazer parcerias com seus alunos no sentido de mobilizar tarefas para que o Curso de Férias possa ser disseminado por todas as salas de aula.

$\mathrm{Na}$ esteira dos Cursos de Férias e dos experimentos calcados no Método Científico, vieram também as indagações sobre a viabilidade ou não das verdades científicas contidas nos livros didáticos. Por vezes, essas certezas foram colocadas em questão diante de fatos novos que surgiam a cada experimento e que não se encontravam nos textos escolares.

É preciso, portanto, transformar a ação pedagógica transformando o fazer do professor. A transmissão pura e simples dos conteúdos sem contextualização precisa se alterar, de modo que possa desestabilizar as bases cognitivas dos alunos e remetê-los a observações e reflexões constantes.

AS LIMITAÇÕES OBSERVADAS: AS DIFICULDADES DOS PROFESSORES EM CONSTATAR, NA PRÁTICA, CONTEÚDOS POUCO EXPLORADOS PELOS LIVROS DIDÁTICOS.

Muitos professores, apesar de estarem observando e manuseando "na prática" os diversos sistemas que formam o corpo dos animais, não conseguiam vislumbrar que os mesmos mostravam-se nos experimentos mais claros do que quando lidos nos livros didáticos ${ }^{3}$. $\mathrm{Ou}$ seja, percebemos a dificuldade que os professores têm em romper com os conteúdos programáticos da Ciência Imobilizada ${ }^{4}$. Apesar de lerem os livros, não conseguem ver o que leem nos experimentos.

Apesar de estarem atentos às observações acerca das experimentações, muitas evidências foram, de certo modo, questionadas por diversos professores, pois entravam em confronto com conhecimentos há muito adquiridos nos compêndios didáticos e repassados integralmente para os educandos sem muitas contestações.

Ao mencionar a relação da inteligência com o fazer prático das mãos, Alves (2003, p. 53) afirma que "o caminho para inteligência passa através das mãos. Pensamos para ajudar as mãos. Das mãos nascem às perguntas. Da cabeça nascem às respostas. Se a mão não pergunta, a cabeça não pensa".

Com isso, será necessário que os professores, enquanto formadores de consciências críticas, busquem estratégias para que eles próprios, diante dos problemas que foram evidenciados, desenvolvam habilidades para realizar essa conexão entre as informações que possuem e a capacidade de pensar criticamente através da experimentação e da resolução de problemas. Sobre essa temática, Hernández (1998, p. 72) afirma que "aprender a pensar criticamente requer dar significado à informação, analisá-la, sintetizá-la, planejar ações, resolver problemas, criar novos materiais ou ideias... É envolver-se mais na tarefa de aprendizagem".

\section{SE HÁ FALHA, ELA É SEMPRE DO OUTRO.}

Nenhum educador presente no evento ventilou a possibilidade de que, além de todas as mazelas indicadas por eles, poderia estar implícito que o trabalho docente podia estar passando por uma crise de alheamento o que impediria o olhar para si mesmo.

\footnotetext{
${ }^{3}$ Alves (2003c) afirma que a primeira missão do professor é ensinar a ver, bem como considera que o pensamento segue a experiências das mãos.

${ }^{4}$ Bachelard apud Oliveira (2000, p. 95) considera como a Ciência que apenas satisfaz o que prevê o currículo, principalmente o de acesso à universidade.
} 
Werneck (1998, p.29) afirma que "habitamos a pátria do 'faz de conta', todos nós fingimos alguma coisa e alguns fingem pagar e outros fingem trabalhar". É cada vez mais importante que a prática reflexiva dos educadores sobre sua vida profissional, seja permanente, para que possam perceber alternativas e omissões em sua atividade docente e assim criar estratégias para amenizar o problema.

Fica claro portanto que a busca de alternativas, através de experimentos calcados no Método Científico, pode alterar a atitude dos alunos do estado passivo em que se encontram para um estado ativo, que o método pode criar. Preparar os professores para atender a esta nova possibilidade é etapa preliminar e essencial.

\section{O PAPEL DOS MONITORES NA CONDUÇÃO DAS DISCUSSÕES ACERCA DOS PROBLEMAS LEVANTADOS.}

A ação dos monitores que participaram dos cursos deu-se apenas no sentido de conduzir as discussões, dando para os professores e alunos apenas informações ${ }^{5}$ básicas. Segundo Morin (2004, p. 18), "a informação é uma matériaprima que o conhecimento deve dominar e integrar (...) O pensamento é mais do que nunca, o capital mais precioso para o indivíduo e a sociedade". A atitude dos monitores de estimular a pensamento reflexivo gerou hesitação nos alunos. Diante da sua indigência frente aos questionamentos levantados e da ausência de respostas prontas por parte dos monitores do curso, ficou evidenciada a maneira caduca de educar que a escola vem disseminando nos quatro cantos do Brasil. Acreditamos que esse foi um dos grandes fatos transformadores que pudemos observar durante o transcorrer de todos os Cursos de Férias: alunos e professores com uma enorme dificuldade de pensar de forma coerente e critica diante das peças anatômicas estudadas e dos experimentos.

Apesar das dificuldades elencadas como, por exemplo, a fragilidade da escola atual em promover efetivamente o pensar coerente diante dos problemas apresentados, observou-se evolução cognitiva concreta ao final do Curso, quando durante a exposição dos seminários de pesquisas, os alunos mostraram-se mais seguros, respondendo com clareza, precisão e criatividade aos questionamentos abordados acerca dos trabalhos por eles desenvolvidos.

Ainda sobre essa dificuldade apresentada por muitos professores de não fornecer todas as informações aos alunos para solucionar um problema, Bizzo (2001, p. 50) considera que "o professor deveria enfrentar a tentação de dar respostas prontas, mesmo que detenha a informação exata, oferecendo novas perguntas no seu lugar, que levassem os alunos a buscar a informação com maior orientação e acompanhamento".

Por isso, constantemente, os monitores devolviam aos docente-discentes as perguntas por eles feitas (por exemplo, por quê?). Como nas palavras de Vigotsky apud Cury (2003, p. 129): "o conhecimento pronto estanca o saber e a dúvida provoca a inteligência".

A complexidade do mundo e da cultura, muitas vezes, leva os indivíduos a precisarem observar os problemas com múltiplas lentes. Essa multiplicidade de olhares, vez por outra, precisa de várias facetas do conhecimento científico existente (SANTOMÉ, 1998). Só assim os conhecimentos podem ser construídos de forma consistente e permanente.

A GUISA DE CONCLUSÃ O: A APRENDIZAGEM BASEADA EM PROBLEMAS COMO PERSPECTIVA DE MUDANÇA NO FAZER PEDAGÓGICO DAESCOLA.

Os depoimentos discentes e docentes coletados ao término dos Cursos de Férias acerca da metodologia ABP reforçam claramente a probabilidade de se implantar a metodologia na escola. Os conceitos emitidos sobre a dinâmica do curso ficaram oscilando entre excelente e bom, o que nos mostra claramente que há esperanças para a mudança, bastando que alunos e professores possam criar

\footnotetext{
${ }^{5}$ Morin (2004, p. 15) aponta que "as informações constituem parcelas dispersas do saber". Com isso, o trabalho dos monitores centrou-se apenas nesse sentido. $\mathrm{O}$ ato de ligar, religar, ponderar, averiguar, coordenar, dar sentido coerente às informações, ficou sob a responsabilidade docente e discente.
} 
estratégias simples para que a coisa realmente aconteça.

Da mesma forma, a experimentação para resolver problemas reais foi apontada por todos (oitenta por cento dos participantes) como sendo o grande desafio do professor em introduzir novamente essa prática nas salas de aula. Segundo Hennig (1998, p. 140), “a atividade experimental é capaz de proporcionar o conhecimento. O conhecimento é melhor adquirido por meio da experiência ativa, em que o aluno tem oportunidade de resolver dificuldades reais".

Outro fato que foi verificado com as pesquisas foi a ausência da experimentação utilizando animais nas escolas. De todos os entrevistados, somente cerca de quatro por cento alguma vez na sua vida escolar experimentou utilizando animais nas pesquisas. A partir do momento em que o professor, de maneira coerente e precisa, discute com seus alunos Bioética e Biossegurança e a necessidade e os objetivos de tais procedimentos, a experimentação com animais poderá ser um ingrediente a mais na perspectiva de estimular os alunos a participarem positivamente das aulas. O conhecimento consciente acerca da contribuição dos animais de experimentação para a vida humana no planeta, os limites éticos e indicações precisas da necessidade de seu uso tornam os alunos muito mais cuidadosos e atenciosos com os animais e a vida de um modo geral.

É interessante que o docente tenha consciência de que a perspectiva experimental definida nos Cursos de Férias recomenda uma maneira diferente de se valer da experimentação. A mesma, nesse sentido, tem por desígnio levar os alunos a pensarem sobre os problemas levantados pelos participantes. A experimentação apresenta-se como possibilidade de confirmar ou negar hipóteses levantadas nos grupos. Levar os alunos a pensar (RATHS, et. al. 1997) é o modelo que a experimentação em sala de aula almeja.

A ação dos monitores durante os processos experimentais também foi apontado por todos como sendo uma postura que de forma consciente levou os alunos e professores a desestabilizarem/incorporarem antigos conceitos e ressignificá-los, para que pudessem dar conta dos problemas propostos. Não dar de pronto as informações que se precisa para solucionar dificuldades encontradas são procedimentos que também levam os alunos a pensar (BIZZO, 2001). Os envolvidos precisam ser movidos pelo desejo de descobrir o novo para que possam aprender. "O milagre da educação acontece quando vemos um mundo nunca visto" (ALVES, 2003b, p. 16).

\section{REFERÊNCIAS}

ALVES, R. Conversas Sobre Educação. Campinas (SP): Verus Editora, 2003a.

. É Preciso Aprender a Brincar. São Paulo (SP), 2003b. Disponível em: $<$ http://www.rubemalves.com.br $>$. Acesso em 15 nov. 2004.

- Que Pipoquem Experimentos. São Paulo (SP). 2003c. Disponível em http://www1.folha.uol.br/folha/sinapse. Acesso em 16 nov 2004.

BERBEL, N.A.N. A Problematização e a Aprendizagem Baseada em Problemas: diferentes termos ou diferentes caminhos? Londrina (PR), 1998. Disponível em $<$ http://www.interface.org.br/artigos2.asp?nCo dartigos $=8>$ Acesso em 02 mar 2005 .

BIZZO, N. Ciências: fácil ou difícil? São Paulo (SP): Ática, 2001.

BRASIL, Secretaria de Educação Fundamental. Parâmetros Curriculares Nacionais: Ciências Naturais. Secretaria de Educação Fundamental. Brasília (DF): MEC/SEF, 1997.

CURY, A. Pais Brilhantes, Professores Fascinantes. Rio de Janeiro (RJ): Sextante, 2003.

GADOTTI, M. Boniteza de um Sonho. Ensinar e Aprender com Sentido: desafio do processo ensino-aprendizagem. IN: Anais do Congresso Internacional de Educação. Autores Associados. João Pessoa (PB): Editora Universitária, 2004. 
HENNIG, G.J. Metodologia do Ensino de Ciências. 3.ed. Porto Alegre (RS): Mercado Aberto, 1998.

HERNÁNDEZ, F. Transgressão e Mudança na Educação: os projetos de trabalho. Porto Alegre (RS): ArtMed, 1998.

JÚNIOR, O.A. O Papel do Construtivismo na Pesquisa em Ensino de Ciências. IN: MOREIRA, M.A. (Editor). Investigações em Ensino de Ciências. v.3. Instituto de Física. Rio Grande do Sul(RS): UFRGS, 1998.

MALHEIRO, J.M.S. Panorama da Educação Fundamental e Média no Brasil: o modelo da Aprendizagem Baseada em Problemas como experiência na prática docente. 2005. Dissertação (Mestrado em Educação em Ciências e Matemática) - Núcleo Pedagógico de Apoio ao Desenvolvimento Científico, Universidade Federal do Pará. Belém (PA), 2005.

MORIN, E. A Cabeça Bem-Feita: repensar a reforma, reformar o pensamento. Rio de Janeiro (RJ): Bertrand Brasil, 2004.

MOYSÉS, L.M. O Desafio de Saber Ensinar. Campinas (SP): Papirus; Rio de Janeiro (RJ): EDUFF, 1995.

OLIVEIRA, R.J. A Escola e o Ensino de Ciências. São Leopoldo (RS). UNISINOS, 2000.

PERRENOUD, P. Construir as Competências desde a Escola. Porto Alegre (RS): ArtMed, 1999.

RATHS, L.E.; JONAS, A.; ROTHSTEIN, A.M.; WASSERMANN, S. Ensinar a Pensar. São Paulo(SP): EPU, 1997,

S A N TOMÉ, J.T. Globalização e Interdisciplinaridade: o currículo integrado. Porto Alegre (RS): Artes Médicas Sul Ltda, 1998.

SANTOS, B.S. Introdução a uma Ciência PósModerna. Rio de Janeiro (RJ): Graal, 1989.
, B.S. Um Discurso Sobre as Ciências. $11^{\mathrm{a}}$ ed. Portugal Afrontamento, 1999.

, B.S. A Crítica a Razão Indolente: contra o desperdício da experiencia - para um novo senso comum: a ciência, o direito e a política na transição paradigmática. $4^{\mathrm{a}}$ ed. São Paulo (SP): Cortez, 2002,

SILVA, M.H.S; DUARTE, M.C. O Diário de Aula na Formação de Professores Reflexivos: resultados de uma experiência com professores estagiários de Biologia/Geologia. IN: Revista Brasileira de Pesquisa em Educação em Ciências. V.1, N², MAIO/AGO, 2001.

WERNECK, H. Se você finge que ensina, eu finjo que aprendo. Petrópolis (RJ): Vozes, 1998. 